\title{
Perceptions and Reality of Agro Forestry Practices in Oku, Cameroon
}

\author{
Godwill Tobouah Nyanchi, Moupou Moise \\ Department of Geography, University of Yaoundé 1, Yaoundé, Cameroon \\ Email address: \\ goddy288@yahoo.com (G. T. Nyanchi), mmoupoul@yahoo.fr· (M. Moise)
}

To cite this article:

Godwill Tobouah Nyanchi, Moupou Moise. Perceptions and Reality of Agro Forestry Practices in Oku, Cameroon. Journal of Human Resource Management. Vol. 7, No. 4, 2019, pp. 78-86. doi: 10.11648/j.jhrm.20190704.11

Received: May 9, 2019; Accepted: July 4, 2019; Published: October 23, 2019

\begin{abstract}
Every farming engagement is geared at obtaining utmost output. Small scale farmers draw knowledge of sustainable agro forestry practices either from resource persons or institutions. Appropriately, practical farming processes are done at an individual scale with the intension of obtaining maximum outcomes. This matches with perceptions and reality of agro forestry commitment undertaken by local farmers. This study underscores the different agricultural techniques practiced in Oku. This write up explores information gathered from focus groups, clear-cut direct observation from sowing, weeding, harvesting and storage of produce, interview of local farmers, and spot visits to selected farms within the locale. The biophysical setting of the milieu favours the practice of agro forestry. Farmers' perception and expectations were investigated using field data, statistical findings and interview results. Obtained results revealed the positive correlation existing between perceptions and reality in the quality, quantity and variety of outputs obtained at the end of the farming season. Local techniques harnessed with modern methods positively matches perceptions and reality in this domain.
\end{abstract}

Keywords: Perceptions, Sustainable Practices, Agro Forestry, Output, Farmers

\section{Introduction}

Agro forestry remains the dominant form of cultivation put into practice by farmers in Oku. Over the years, changes in farming techniques have been recurrent, but the adoption of sustainable agro forestry methods remains unbeatable. However, it is the most cherished form striking the expected balance between cultivation methods and food supply. Indigenous farmers adhere to this form of cultivation as a result of the numerous benefits obtained. Evidently, field findings revealed the close tie existing between cultivation techniques and output. With the numerous gains acquired the introduction of new seed species hold the farmers spellbound. Innovation remains a welcome gesture in this practice. Farmers adopting innovations are growing in leaps and bounds. The chain fashioned by this practice enlarges the multiplier effects on the society and the environment. Self sufficiency and environmental stability is not outweighed.

\section{Methodology}

\subsection{Questionnaires Administration}

Primary data was collected using questionnaires. Questionnaire formulated to guide this study were designed in three types namely; structural questions, non structural and semi structural questions. For convenience and ease of work from the researcher's previous knowledge, the study area was divided into quarters. To ease distribution, the area was divided into smaller zones. Some households were systematically chosen to administer questionnaires. Some farmers were equally contacted in their farms. Information gathered from the questionnaires complemented the survey.

\subsection{Interviews}

Here, formal and informal interviews were used to gather invisible data. Formal interviews were conducted with resource persons involve directly or indirectly in the practice 
of agro forestry. In all twenty (20) formal and thirty five (35) informal interviews were granted. Data obtained was assembled and then grouped in terms of similar and varied responses in respect to different domains of activity.

\subsection{On Farm Visits}

More than seven farm visits were carried out. The numerous visits carried out permitted the identification of agricultural techniques, specific trees planted on farms to improve agricultural production, different periods of farming activities such as planting, weeding and harvesting of crops. In this light farm visits assessed farmers' activities at the different times.

\subsection{Focus Group Discussions}

Common Initiative Group discussions on agricultural practices were taken into consideration. Attention centred on their ideas on improving agricultural production and the strategies to adopt.

\section{Result}

Field gatherings revealed that increased in agro forestry output is as a result of acquired farming techniques rather than inherited. Acquired practices sustainably managed leads to prolonged periods of increase output realization. Indeed perceptions, ingenuity and hard work remain a better way of matching output. Farmers in this locality are exposed to numerous challenge thus empowering them to keep the flame of hard work burning. In a nutshell, their perceptions are realized in outputs obtained.

\section{Discussion}

\subsection{Incommensurate Surface Area Destined for Agro Forestry Cultivation}

Field gatherings point to the fact that the surface area destined for cultivation is progressively diminishing in size. It is against this background that adopted techniques are tailored to match expected crop output to meet up with the ever increasing demands of family food needs. This is achieved through the numerous innovative methods put in place and adopted by the farmers [1]. A majority of local farmers adhere to these techniques overriding ancient ways and methods. The stagnant land even though decreasing in size in respect to cultivation is forced to absorb cultivation pressure mounted on it. Facts point to the decrease in surface area over the years as seen in table 1 .

Table 1. Farm land decrease in Oku from 1979-2012.

\begin{tabular}{lllllllllllll}
\hline & $\mathbf{1 9 7 9}$ & $\mathbf{1 9 8 0}$ & $\mathbf{1 9 8 1}$ & $\mathbf{1 9 8 2}$ & $\mathbf{1 9 8 3}$ & $\mathbf{1 9 8 4}$ & $\mathbf{1 9 8 5}$ & $\mathbf{2 0 0 8}$ & $\mathbf{2 0 0 9}$ & $\mathbf{2 0 1 0}$ & $\mathbf{2 0 1 1}$ & $\mathbf{2 0 1 2}$ \\
\hline Surface area in hectares & 34920 & 35050 & 35100 & 36000 & 38500 & 39000 & 39600 & 11.321 & 10800 & 10100 & 9085 & 9057 \\
\hline
\end{tabular}

Source: Drummond Hay 1969, Godwill Tobouah 2015 and SDDARD

Table 1 reveals the evidence of a drastic decrease in cultivation lands surface over the years. In 1979, the total land surface put under cultivation in Oku stood at 34920 hectares. In 2012, these vast areas under cultivation dropped to 9057 hectares. This decrease in terms of percentages stands at $25.93 \%$. Land decrease in size in Oku has been progressive. From research findings gathered, this decrease in land surface has been marked by a rapid increase in population within the locality. In 1979, Oku's population was 32.988 inhabitants and in 2005 the population stood at 87720 inhabitants [2]. On the other hand, feeding this ever increasing population remains a challenge within the study area. In 2018, the land surface destined for cultivation stands at 8450 hectares.

\subsection{Sustainable Agricultural Practices Favouring Increase Crop Yields}

With the advent of innovation adoption, traditional farming techniques gradually gave way to modern and sustainable techniques of agro forestry. Techniques such as slash and burn methods and over cropping gradually gave way to sustainable ways of cultivation. Fallow periods gradually reduce but were accompanied by the planting of some indigenous species of trees to maintain soil fertility. The use of home grown seeds gave way to fast and more productive treated seeds. As a matter of fact, production techniques progressively improved upon. The notion of sustainable agriculture gradually gained ground within the study area. Within the context of this study, sustainable agricultural practices involve land management systems therefore increasing overall yield of farms. The integrated components in farms within the past years made perceptions to becoming a reality in the agro forestry background. It is a highly adopted technique and remains the best way of cultivation in Oku. However, despite the improvements in agricultural techniques, areas put under cultivation for the different crops cultivated have been gradually reduced in size as seen in table 2 .

Table 2. Selected crops and areas under cultivation from 2008-2012.

\begin{tabular}{llllll}
\hline Crop & Area \& Production & $\mathbf{2 0 0 8}$ & $\mathbf{2 0 0 9}$ & $\mathbf{2 0 1 0}$ & $\mathbf{2 0 1 1}$ \\
\hline \multirow{2}{*}{ Maize } & Area & 11.321 & 10800 & 10100 & 9085 \\
& Production (tons) & 22642 & 19422 & 17569 & 15868 \\
Beans & Area (Ha) & 11.321 & 10800 & 10100 & 9057 \\
& Production (tons) & 5.661 & 5196 & 4963 & 9005 \\
Solanum potatoe & Area (Ha) & 9.613 & 9452 & 9310 & 9752 \\
\hline
\end{tabular}




\begin{tabular}{lllllll}
\hline Crop & Area \& Production & $\mathbf{2 0 0 8}$ & $\mathbf{2 0 0 9}$ & $\mathbf{2 0 1 0}$ & $\mathbf{2 0 1 1}$ & $\mathbf{2 0 1 2}$ \\
\hline & Production (tons) & 144.188 & 141620 & 138546 & 137100 & 137895 \\
Tomato & Area (Ha) & 85 & 98 & 142 & 250 & 335 \\
Cabbage & Production (tons) & 1700 & 2103 & 3251 & 4521 & 6525 \\
\hline
\end{tabular}

Source: SDDARD annual report 2012 and fieldwork

From a closer look at table 2 above, larger production tonnes of maize, beans, potatoes, yams and fruits are realised within the study area. Percentages of production for the various food crops have not been discouraging proving that much effort are under way to stabilise and improve on production. Surface area under cultivation in 2008 for maize was 11.321 accompanied with a production of 22642 tons. As years passed, this production trends reduced to 19422 , increased to 17569 in 2010, 15868 in 2011 and dropped to 14860 in 2012 . Production trends were equally accompanied by decrease in farm sizes for the various accompanied years. In 2008, area destined for farmlands progressively reduced in size from 11321 to 10800 in 2009, moved from 9085 in 2010 to 9087 in 2011 and finally to 9057 in 2012. In a nutshell, maize production for 2008 and 2012 saw a percentage change of $65 \%$ while surface area changed from 2008 to 2012 by $80 \%$. Generally, a similar trend was experienced in the different crops cultivated within the study area. Beans production and surface area witnessed an $80 \%$ change, Solanumpotatoes had a $95 \%$ change in surface area and total productions.

\subsection{An Enlarged Farming Community}

The majority of the population of Oku are involved in agriculture or related activities at Elak, Ibal, Jikijem, Mbam and Simonkoh. In Oku, more than $85 \%$ of the population are involved in these activities. In an effort to better promote such activities, the study area is divided into agricultural post areas as seen in table 3 .

Table 3. Populations involve in agro forestry practice in Oku.

\begin{tabular}{|c|c|c|c|c|c|c|}
\hline Parameters & Elak & Ibal & Jikijem & Mbam & Simonkoh & Total \\
\hline Total area $\left(\mathrm{km}^{2}\right)$ & 02.5 & 17.5 & 07.5 & 16.0 & 08.0 & 51.5 \\
\hline Total population & 6.850 & 3900 & 4623 & 2400 & 1323 & 19096 \\
\hline Farming population & 5946 & 3690 & 3903 & 1990 & 1220 & 16749 \\
\hline Farm families & 4891 & 2467 & 2836 & 1400 & 1019 & 12613 \\
\hline
\end{tabular}

Source: SDDARD annual report 2018 and Fieldwork

The statistics in table 3 reveal that a total percentage of $87.70 \%$ of the population is involved in agricultural activities in the five quarters above. Elak the headquarters of Oku with a total population of 6850 inhabitants has a total farming population of 5946 with 4891 farm families. It is clear that more than $86.8 \%$ of the inhabitants are involved in agro forestry practices at different levels. Capacity building of agro forestry practices as an impetus to food supply to farmers is the same in Ibal, Jikijem, Mbam and Simonkoh. As a matter of fact, a total number of 19096 inhabitants reside within this locality, with a farming population of 16749 , making up $87.70 \%$ involved in agriculture with about 12613 farm families [3]. This number is grossly disproportionate to the number of Zonal Extension Workers (ZEW) found in Oku. Each agricultural post has just one ZEW.

\subsubsection{Introduction of Crop New Species and Techniques Adopted}

The advent of the KMFP was closely followed by the introduction of new species of crops and fruit trees. Various species were brought and the project opened demonstration farms in which farmers were trained on better management of the latest species. Farmers were drilled on techniques of ploughing, planting, maintaining manures on farms, pruning, harvesting and storing crops. Modern farming methods coupled with improved seedling was recurrent in the area. Unlike in the past where many crops were planted on one ridge, modern methods of planting encourage few crops planted at regular interval to promote healthy growth. Each crop requires different amount and type of nutrients, maximum sunlight and soil nutrients for their growth. In addition, more attention was paid on crop maintenance in farms. Farmers on their part are highly encouraged to weed, prune, water, mulch and spray when the right time comes. Nowadays, the farmers realised the importance of farm maintenance and no farmer neglects his crops on their farms.

Scarlet runnar beans is a new variety of beans introduced by the defunct KMFP. This new variety of beans was identified and shared to farmers and a study was done to know the advantages it had over the other species of beans. The studies carried out proved that the advantages of the Scarlet runner beans were numerous compared to the local types of beans. Amongst these advantages were the following: the new specie did not occupy much space on the farm if well controlled, it had many leaves which provided manure for soil fertility improvement, it acted like a cover crop which kills other notorious grasses on the farms and it grows and bears for about 2 years continuously and is very tasteful. With the numerous advantages it offered, farmers were encouraged to cultivate scarlet beans in great quantities. Farmers were drilled on the importance to continue 
multiplying these specie for future use. In an interview carried out with Mentan Wilfred of Elak, Jiay Angelica Fefeh of Manchok and Elisabeth Yiese Njiakoy of Manchok some of farmers cultivating this bean species testified theirincreases in output. Success recorded encouraged the project to further distribute the species to some 25 farmers within the locality. It should be noted that an innovative way of realising additional output calls for joint collaborative measures between farmers.

\subsubsection{The Place of Oku Farmers in Regional Farmers' Gathering}

Exhibition of agricultural products at shows both at the divisional and regional levels has always been the pride of the Oku peasant farmer. During these shows, farmers exhibit their best produce harvested during the season. Farmers exhibit products depending on their domain of farm specialization. At the Sub-Divisional level the shows are organized grouping farmers from the nooks and crannies. It has been a yearly routine taking place mostly in December. After the mini show, comes the regional show. This show took place at the regional headquarters in Bamenda. Farmers selected from the mini show present their products at the Regional Agro Pastoral Shows. During the regional show the following farmers exhibited their products and ranked in the following positions.

Table 4. Participating farmers at the regional agric show.

\begin{tabular}{llll}
\hline Name of farmer & Product Exhibited & Agric post area & Position \\
\hline Soh Amos Wanyu & Honey \& by-products & Elak & $2^{\text {nd }} p^{\text {prize }}$ \\
Fonkwa Patrick & Wheat & Elak & $2^{\text {nd }}$ prize \\
Messi Mbuh Peter & Solanum potatoes & Simonkoh & $3^{\text {rd }}$ prize \\
Ngum Paul Nkengla & Tomato & Ibal & $4^{\text {th }}$ prize \\
Bonghajum Emmanuel & Coca maize & Simonkoh & $5^{\text {th }}$ prize \\
Chimtom Solomon Kibuh & Coffee seedlings & Manchok & - \\
Chin Adamu Bonbajum & Solanum potatoe ware & Simonkoh & - \\
Yham Amina Mekewi & Coffee/tomato & Ibal & - \\
\hline
\end{tabular}

Source: SDDARD reports and Fieldwork

Table 4 shows the participation of eight selected farmers from Oku to the regional agric show. In this show, farmer's exhibitions reflected their attachment to and progress in the different sub sectors of cultivation. Mr, Soh Amos Wanyu exhibited honey and its by-products. At the regional level, he was the second best presenter, thus projecting the image of Oku's agro forestry practices. Mr, Fonkwa Patrick of Elak also won a second prize for the quality of wheat presented. In the Solanumpotatoesector, Mr, Messi Mbuh Peter of Simonkoh grasped the third prize. In addition, other farmers from Oku occupied both the fourth and fifth positions. Improvements in agricultural practices remain the prior concern of local farmers within the study area.

\subsubsection{Increase in Apiculture in Oku}

One of Oku's prestigious resources is honey. Oku honey is rich in both quality and quantity. Besides farming, beekeeping is one of the economic activities carried out. This activity employs more than 310 bee farmers with an overall bee hives ranging about4500. Annual production falls between 10 to 13 tons (Manager Oku honey society). The main bee loving trees include; Shefflera, Nuxia congesta, Prunus africana, Syzygiumstaudtii and Shefflera is no longer used for carving but conserved for honey. The Fondom Wide Rules (FWR) binding the forest user groups of Kom, Oku and Nso plays an important role in conserving the forest. Individual apiaries and trees planted in farms are given greater attention. Bee farming is an old practice considering the fact that farmers had no umbrella association. Beekeeping projects within the study area started in 1998 with the main objective of training bee farmers and potential bee farmers. These farmers were trained on modern beekeeping techniques. As a source of food and medicine, this domain of agro forestry has striven within the research area.
Modern beekeeping techniques such as the construction and installation of the Kenyan top-bar hives, colony transfer from the traditional hive to the Kenyan top-bar hives, industrial and medicinal uses of hive products, and the introduction of smokers while preventing accidental fires and bee suits. Hives installed in cool areas are more prone to colonization difficulties than those in hot areas. Kenyan top-bar hives colonized in hot areas are successfully taken to the forest. Sources in the field confirmed the good quality and quantity of honey harvested from the Kenyan top-bar hives. Oku honey is unique in taste and colour rendering it high quality honey. The value of honey as a source of income, food and medicine is really boosting the livelihood of the bee keepers. The amount of honey produced fluctuates due to changes in flowering years of some bee-loving tree species. This flowering is favoured by changes in season and successful biodiversity conservation. More than 200 bee hives were constructed and carried to Mbam Oku and some parts of Noni for colonisation. Out of this number, 67 bee hives got colonised before $31^{\text {st }}$ December 2018. This poor colonisation rate is due to the fact that funds came in late and the project started late.

\subsubsection{Practice of Livestock Rearing in Upland and Lowland Areas}

Besides farming, livestock rearing is another important activity carried out within the study area. It involves the rearing of goats, sheep, pigs, cattle, and horses either on a small or large scale to supplement family income and food. This practice dates as far back as the $19^{\text {th }}$ century. It is practised both by the Bororos and a minor fraction of the natives of Oku. A larger number of livestock within the area is found within the forest. This is due to the vast grazing lands at their disposal; the forest also serves as a shade to the large livestock numbers. Each livestock carries the mark of 
the owner on the ear. This sub branch of agro forestry contributes a significant ratio to food supply. Livestock numbers have drastically witnessed an increase in Oku [4]. The trend has been marked by the innovations and constant vaccination of livestock by the numerous veterinary doctors spread within the study area. These vast cattle numbers are a measure to boost agro forestry practice in Oku as is the case in other area. It is practiced as an economic activity, for those involved in the practice.
Crops and fruits harvested are sold in the local markets in and around Oku. On market days locally called Ngokse, farmers converge to sell their agricultural produce at the Elak market. Prices are determined by the individual farmers for items like a bunch of plantains, sugar cane, cocoyams and other vegetables. Food items such as beans, ground nuts, potatoes and soya beans are measured using buckets of different sizes such the $5 \mathrm{~L}, 10 \mathrm{~L}$, $15 \mathrm{~L}$ or $20 \mathrm{~L}$. Table 5 shows different food items and their prices as sold in the various markets in Oku.

\subsection{Marketing of Agro Forestry Products}

Table 5. Different food items and their prices sold in markets in Oku.

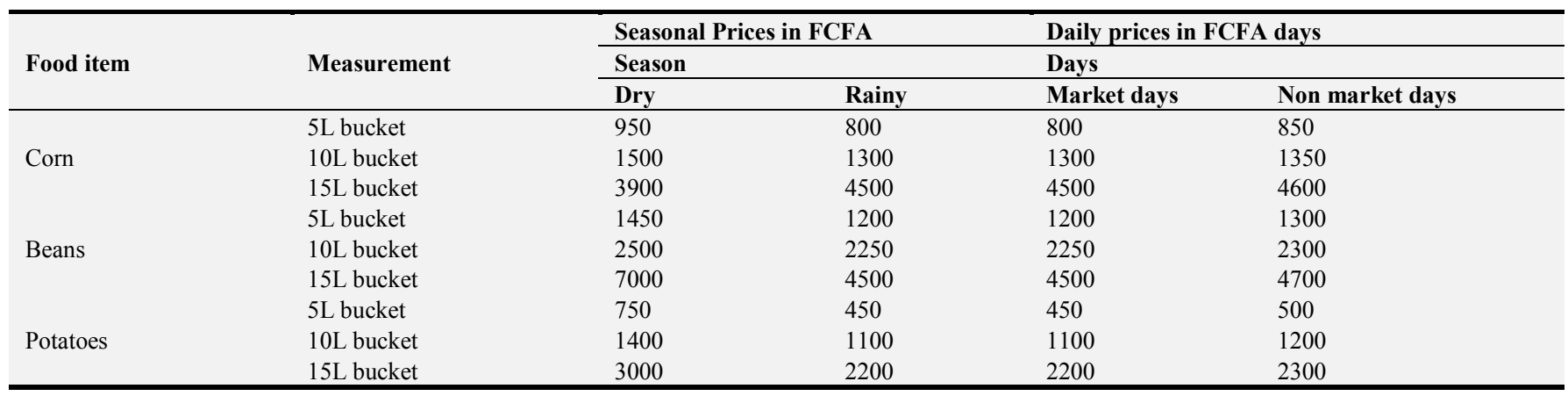

Source: Field work 2018

Prices of these different food items vary considerably according to season and days of the week. During the harvesting season, there is a fall in prices for some food items. In general, food items are relatively cheaper in Oku than the neighboring villages. On Oku market days (Ngokse), prices equally witness a slight reduction compared to non market days. Retailers of these products buy them from farmers very early upon their arrivals in the market.

\subsection{Agro Forestry Practice and Zonal Extension Workers (ZEW)}

Under the supervision of the Divisional Supervisor Mr. Kwei Gregory at the Divisional Delegation for Agriculture in Bui, ZEW works under the PNVRA extension program. OkuNoni area makes up one of the extension program under his supervision Bui Division has $44 \mathrm{ZEW}$ and Oku has $5 \mathrm{ZEW}$. Table 6 shows training themes organised by the ZEW.

Table 6. Training Themes organised by the ZEW ZEW.

\begin{tabular}{ll}
\hline Crop & Themes \\
\hline & Appropriate Fertilizer / Organic Manure Application Techniques \\
Maize & Grain Storage Techniques \\
& Stalk Borer Control Techniques \\
Beans & Appropriate Storage Techniques \\
Solum potatoe & Seed Selection and Treatment Techniques \\
Ground nuts, soya beans & Appropriate Cultural Practices \\
Onions & Appropriate Cultural Practices \\
Coffee seedlings & Appropriate Nursery and Cultivation Techniques \\
& Harvesting and Storage Techniques \\
Cattle, pig andruminant & Coffee Seedling Nursery Techniques \\
& Pasture Improvement Techniques, \\
& On - Farm Feed Formulation and Feeding Techniques \\
& Mineral Leak Production Techniques \\
\hline
\end{tabular}

Source: Divisional Delegation for Agriculture Bui and Fieldwork

From these themes, farmer groups in their respective zones the practically work in their respective zones. ZEW workers play their traditional advisory roles to the farmers. More emphasis is placed on the cultural practices and techniques under areas and crops cultivated. The farmers are also sensitised on modern methods of land preparation and cultivation. Semester reports on the extent of realisation of the themes are forwarded to the delegate by the ZEW at the end of each semester.

\section{Capacity Building of Farmers}

Farmers in the different zones in Oku receive trainings at 
various levels from zonal workers. A glaring example is that of the agricultural post situated at Simonkoh which covers the Nkwi area. It is under the control of Mrs. Ngum Gwendoline and she is responsible for building farmers' capacity within this zone from knowledge and skills learned at the divisional level. This is done through weekly meetings, visits to demonstration farms, focus group discussions and trainings. This is successfully carried out with the CIG found in the zone. Weekly meetings are held with the farmers especially on country Sundays to enlighten the farmers on new cultivation techniques. In a focus group discussion with Kofkechekle Mixed Farming Group of Simonkoh on the $11^{\text {th }}$ of July 2018, the theme for training was on harvesting and storage techniques. This theme coincided with the periods of harvesting for some food crops within the locality. The extensive nature of this zone makes the coordination of these meetings extremely difficult to the zonal worker. The surface area covered by the zone is $39 \mathrm{~km}^{2}$ with a total population of 11.395 and about 9.116 farmers. It is tedious as she is alone and has to covers long distances on foot. There is no means of transportation put at her disposal.

\subsection{An Innovative Approach to Small Scale Farmers}

Various innovative techniques are taught to small scale farmers by ZEW. The study area is divided in to five agricultural unit and farmers in the different quarters fall under an agricultural post under the supervision of a ZEW. Training programmes on themes such as grain storage techniques, appropriate fertilizer application, organic manure application, seed selection and treatment techniques are taught to the farmers by ZEW. In cognisance with the trainings received by the farmers, inputs and farm tools are equally brought closer to the farmers improve on their agro forestry practices. These inputs are obtained at the OACU LTD at cheaper prices especially when buying is done at the group level. In this light, the numerous CIG present in Oku buy these inputs at a relatively cheaper price. In 2018 the following pesticides and farm tools were in stock at the OACU LTD.

Table 7. Pesticides and farm tools in stock at the OACU LTD

\begin{tabular}{lll}
\hline Description & Quantity & Stock \\
\hline Herbicides (L): Round up & 119 & \\
Plantop & 55 & \\
Herbistar & 55 & \\
Fungicides (sachets) & & \\
Metrostar 500WP & 57 & 50 \\
Callomil & 213 & 100 \\
Hydrox & 436 & \\
Plantomil & 110 & 40 \\
Caocobre & 283 & 47 \\
Ridomul & 319 & \\
Insecticieds (L) & & \\
Plantima 30SC & 58 & 10 \\
Farm tools; Tarpuline & 28 & \\
Secateur & 63 & \\
Digging & 71 & \\
Rain boots & 47 & 150 \\
Safety goggles & 239 & 100 \\
Gas mask & 239 & \\
Hawk saw & 26 & \\
\hline
\end{tabular}

\begin{tabular}{lll}
\hline Description & Quantity & Stock \\
\hline Watering can & 34 & \\
Sprayer & 95 & \\
\hline
\end{tabular}

Source: OACU LTD records and fieldwork

\subsection{Harvesting and Rural Storage of Agricultural Produce}

The research reveals that more than $95 \%$ of rural farmers store their harvest using local techniques. After harvesting maize, it is dried using the sun and stored in locally made barns. The barns are made from plank or bamboo. Dried maize can be stored for more than three months. In addition, beans are dried and stored in the ceiling of the local kitchen. The ceiling is regularly supplied with heat from the burning of fire in the kitchen. After the bean is dry, they are peeled off the pods and can be stored in bags either for subsequent consumption or for sale. After harvesting, ground nut is equally dried in the ceiling. Tubers such as cassava and cocoyams are mostly stored in the stored in the soil or left unharvested for sometime. In Oku, there are specially designed baskets used by women to carry farm produce such as corn, beans and yams. The content of these baskets can be measured to a tin bucket, which is about 15 litres [5]. These are some of the carrying method and storage technique used to promote agro forestry in Oku. This is because the basket facilitates the transportation of some agro forestry crops and the barn serves in storage.

\subsection{Rural Development Institutions in Support of Agro Forestry Practices}

The practice of agro forestry within the sub division is not only left in the hands of the farmers alone. Their individual efforts are joined by some specialised institutions to strengthen production and boost output. Based on the fact that more than $80 \%$ of the rural dwellers in Oku are peasant farmers, most of the rural development institutions intervening are tailored to promote agro forestry related activities while combating rural poverty. Their actions and support to the rural farmers cannot be under estimated. Through these specialised institutions, different sectors are touched giving birth to positive results. Indeed, the sub division is an attraction pool to development institutions.

\section{Problems Linked to Agro Forestry Practice and Food Supply in Oku}

The problems of matching perceptions to reality in terms of output are numerous. However, the problems make the farmers' more determined than ever to increase their output.

\subsection{Local Techniques Versus Transition to Modern Agro Forestry Practice}

The practice of modern agro forestry as an innovative process is equally accompanied by its own nature of 
problems. The transition to modern agro forestry with the use of fast maturing seeds and species is not without problems. The concept of agro forestry is new and the ideas need to be diffused from the core to the periphery. It needs to be spread throughout Oku. Likewise any new idea to be spread faces some barriers. Contrary views stem from the destruction of aged fruit trees, the abandonment of local seeds in favour of new species, adaptation to new methods of cultivation and so on. This transition was not smoothly welcomed in Oku. Even though the resistance is less today because of the benefits seen from this agro forestry practice, much still needs to be done.

\subsection{Management and Complex Nature of Agro Forestry System}

The integration of trees, crops and animals on the landscape possess a rather complex situation to manage. This complexity leaves the local farmer with no choice than to adapt strategies to maintain a certain level of output from their farms. Indeed, the crops have limited space to grow as the farmer strives to maximise his limited farmland.

\subsection{Socio-cultural Myths and Beliefs Regarding Cultivation Techniques}

The beliefs of the natives in relation to the modern techniques introduced takes a long time of implementation. Such belief as new variety of corn, potatoes and beans are of low quality in terms of taste. This myth is an old age tradition of the elderly persons in the community [6]. The elderly persons on their part discourage the planting of treated corn, beans and potatoes seeds on their farms. However, the youths who constitute a majority of the active population and those involve in agriculture prefer the modern seedlings. At this level, their harvest is great and food supply is gradually on the rise. Fruits from vegetative propagated trees such as mangoes, avocados, guavas, oranges and pineapples are considered by the elderly as tasteless fruits. Their bigger sizes and attractive colour scares the elderly persons who prefer the locally grown species of fruits. About $65 \%$ of the elderly population of Oku avoid the consumption of such fruits. They consider them to be fruits for the younger generation. That is why it is common to hear an elderly person describe some fruits or food crops as food for the young. Indeed, this is the socio cultural myth attached to the practice of agro forestry within the locality. However, the percentage of change is really on the rise as the modern techniques and seeds now dominate the study area.

\subsection{Destruction of Forest by Rampant Bush Fires}

April 2000 was the most disastrous month in Kilum - Ijim forest as bush fires burnt 2560 hectares of the forest, 665 hectares on the Kilum site and 1895 on the Ijim site [7]. The following communities lost the following estimated areas as shown by the computer from the Global Positioning System (GPS) readings which were collected round the burnt areas. The fire fighters were assisted by project technicians to produce a participatory assessment of forest cover burnt by the fires. Table 8 shows the total area burnt by the April 2000 bush fires.

Table 8. Area burnt by the April 2000 bush fires.

\begin{tabular}{|c|c|c|c|c|c|c|c|c|}
\hline Quarters & Mbockevu & Ngemsiba & Kisotin & Lang & Jikijem & Mboh & Keyon & Simonkoh \\
\hline Area lost hectares & 102 & 115 & 189 & 203 & 9 & 15 & 3 & 29 \\
\hline
\end{tabular}

Source: Manager's magazine No13 Dec. 2000

Since 2013 up to 2019, there has been no incidence of bush fires in Oku. In February 2003, the worst fires in the history of the forest occurred in Oku. A forest fire of such magnitude had never occurred within the Kilum forest. Most of the area burnt was degraded and had been under cultivation in the past years. This disastrous fire burnt 2024.9 hectares out of a total forest area of 4229 hectares. Percentage of area lost to the fires stood at $47.88 \%$. The fire left an indelible mark on the minds of eye witnesses. There was a general mobilisation to put out the fire. Such fires occurring during the dry season are dangerous and would probably consume a wide area which was the case in the Kilum forest. This fire led to the death of one forest user, a thing which has never been heard in Oku. Forest users were once hit again because their main source of income had been threatened. A general feeling of disappointment reigned amongst the users. Their precious resource protected for years had been destroyed. The forest lost much of her biodiversity in these fires. Table 9 shows the area lost to the fires in the different forest management institutions in Oku.

Table 9. February 2003 fire disaster and area covered.

\begin{tabular}{|c|c|c|c|c|}
\hline Forest management institution & Total area (hectares) & Area burnt & Area left & \% Burnt \\
\hline Emfveh mii & 909 & 160.5 & 748.5 & $17.6 \%$ \\
\hline Mbai & 484 & 103.9 & 380.1 & $21.46 \%$ \\
\hline Nchiiy & 974 & 643.7 & 330.3 & $66 \%$ \\
\hline Bihkov & 1932 & 1116.7 & 815.3 & $57.8 \%$ \\
\hline Total & 4299 & 2024.9 & 2274.1 & $47.10 \%$ \\
\hline
\end{tabular}

Source: KMFP post fires report Feb. 2003

From table 9 above, four FMI's were affected by the fire. A total surface area of $47.88 \%$ was lost to the fires. The Emfveh mii area covering adjacent areas of the forest such as
Ngvuinkei II, Manchok, Keyon, Ngashie and others. This area is one of the richest patches the KMF. This rich patch of the montane forest is found above central Oku and extends 
up to the mountain summit. In this zone the fire burnt 160.5 hectares out of a total surface of 909 hectares. The percentage lost to the fires within the zone stands at $17.6 \%$. The community is highly involve in carrying out livelihood activities in the forest such as bee keeping, fuel wood collection, bamboo harvesting for the construction of houses and hives, the harvesting of medicinal plants, rat trapping (commonly referred to as Oku sardine) and the harvesting of wild vegetables [8]. This zone also harbours most of the livestock kept in the forest in Oku. The Bikov FMI is made up of villages such as Mvem, Vekovi, Kai and Ntur. This zone is found on the Nso area of the forest. Here, the destruction was enormous as more than half of the surface area was lost to the fires. Out of a surface area of 1932 hectares, 1116.7 hectares were consumed by fire making a total percentage of $57.8 \%$ lost. Mbai FMI lost 103.9 hectares out of 484 hectares. The area lost in this zone was equally high. A total percentage of $21.46 \%$ was lost to the fires. The greatest area lost to the fires was in the Nchiiy FMI where $66 \%$ of the forest was completely damaged. Out of 974 hectares, 643.7 hectares was burnt. The Nchiiy / Mbai commission of inquiry named Pa Galius Wirba as the prime suspect of the fire. Field investigations gathered that the source of these fires came from the Nchiiy FMI and latter spread to the other zones. In all, the damage caused by this fire did not spare bee farmers. Their post fire records on the number of hives burnt was dramatic [9]. An alarming total of 1707 beehives were burnt in this disastrous fire in 2003. These included both colonised and the none colonised beehives. These include bee hives in the four zones touched by the fires. As a consequence, honey production was at a decline in the 2003 harvesting season. In a nutshell, the agro forestry sector in Oku was hard hit by this fire and it greatly affected the entire community [10].

\section{Improving Livelihood in Oku Through Agro Forestry}

Challenges in improving livelihood remain a major priority in rural communities in Oku today. Agro forestry practices intervene with a strong potential of improving land-use thus offering opportunities to agricultural productivity. Within the study area, $52 \%$ of farmers clearly expressed the view that this practice has greatly improved their livelihoods. Findings reveal that mixed cropping systems made of annual crops and planted fruit trees such as mangoes, avocados, plantains, kola nuts, guavas and oranges are all income generating. This system is highly cherished by farmers because it allows them to make their choices and combinations according to their needs, values and priorities in order to generate continuous revenue from their farmlands.

\section{Conclusion}

Efforts put in by farmers are accompanied with the adoption of modern agro forestry techniques making perceptions becoming a reality. Meeting up with food needs of the ever increasing population of Oku remains a greater challenge to the society. In a nutshell, the research came to the conclusion that "necessity is the mother of invention". The farming systems practised within this area is an adjustment of farmers to the yester years declining soil fertility caused by ignorant ways of cultivation. In a nutshell, there are spectacular innovations in agro forestry practices in the area. In this light, the contribution of agro forestry is marked with innovative techniques geared towards realising additional output. Innovation in land preparation techniques, fast maturing seeds, modern planting techniques, harvesting and storage of produce, modern beekeeping and livestock techniques is a cornerstone to the advancement of the area. It greatly rekindles hope in agriculture which is considered as the backbone of the society. Local farmers adopt at least a modern method of cultivation. Local farmers today are no longer conservatives. They borrow from advanced and developed agro forestry techniques from other areas to ensure increase food supply.

\section{References}

[1] GODWILL Tobouah Nyanchi, 2015, Agro Forestry Practices in Oku Sub-Division: An Impetus to Food Supply and Rural landscape Transformation. Masters Dissertation, Department of Geography. University of Yaounde 1. 149P.

[2] AJIBOLA V., 2009, Contributions of Agro forestry Practice in Ondo State, Nigeria to Environmental Sustainability and Sustainable Agricultural Production.

[3] DEGRANDE Ann., ASAAHZ., TCHOUNDJEUZac, KANMEGNE B., DUGUMA and Franzel S., 2007, Opportunities for and Constraints to Adoption of Improved Fallows: ICRAF's Experience in the Humid Tropics of Cameroon.

[4] EICHER C., and STAATZJ., 1984, Agricultural Development in the Third World, John Hopkins University press.

[5] ENCHAW Gabriel B., 2009, An Assessment of Conservation Strategies in the Management of Natural Resources in KilumIjim Forest Project Area (NWR), Ph.D Thesis, University of Yaoundé 1.

[6] ESWARAN H., Virmani S., Spivey L., 1993, Sustainable Agriculture in Developing Countries: Constraints, Challenges and Choices in Technologies for Sustaining Agriculture in the Tropics, ASA, Madison USA.

[7] FAO, 1992 Conduite de petites enquetes nutritionnelles.

[8] GODWILL Tobouah Nyanchi, 2019, Productivity Challenge of Soils Along the Slopes of Mount Oku in Cameroon. Fluid Mechanics. Vol. 5, No. 1, 2019, pp. 1-7. doi: 10.11648/j.fm.20190501.11.

[9] MOUPOU Moise 1997, Enjeux Spatiaux et Dynamique des Paysage en Pays Bamoun (Quest Cameroun). Revue de Geographie du Cameroun, Vol XIII, N 1 .

[10] OJUKU T., 2005, Dynamics and Impacts of Vegetable Cash Income Population Movement in the Bamboutous Highlands of Cameroon from 1960 - Present. Ph.D Thesis Department of Geography. University of Yaoundé 1 . 
[11] NDIKINTUM J., N., 2000, The Impact of Population Growth and Pressure on Agricultural Land in Oku sub Division NWP, DIPES II Memoir ENS Yaoundé.

[12] NKWAIMBI W., T., 1996, Evolution of Agricultural Zones on Mount Oku, Maitrise Memoir University of Yaoundé I.

[13] KANG B., and AKINNIFESI F., 2000, Agro Forestry as Alternative Land use Production Systems for the Tropics.
[14] NCHAMCHAM Nsungnen O., 2015, The Contribution Of Common Initiative Groups To Agricultural Production In OkuSub-Division, University of Bamenda 91P.

[15] HAWKINS R., and BRUNT G., 1965, The Soils and Ecology of West Cameroon, Volume 1, FAO, Rome, 212P. 